WELL INSTALLATION AND DOCUMENTATION, AND GROUND-WATER SAMPLING PROTOCOLS FOR THE PILOT NATIONAL WATER-QUALITY ASSESSMENT PROGRAM

By Mark A. Hardy, P. Patrick Leahy, and William M. Alley

U.S. GEOLOGICAL SURVEY

Open-File Report 89-396

Reston, Virginia

1989 
DEPARTMENT OE THE INTERIOR

MANUEL LUJAN, JR., Secretary

GEOLOGICAL SURVEY

Dallas L. Peck, Director

For additional information write to:

Geological Survey

Office of Water Quality

National Center

Reston, VA 22092
Copies of this report can be purchased from:

U.S. Geological Survey

Books and Open-File Reports Section

Box 25425, Federal Center, Building 810 Denver, CO 80225 


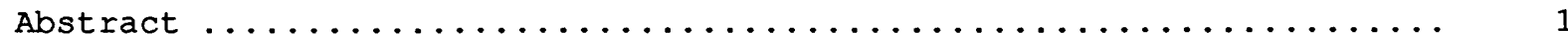

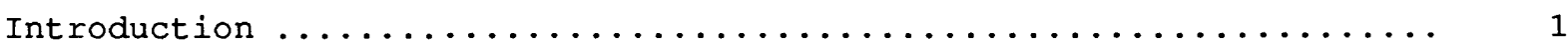

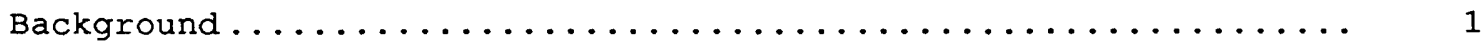

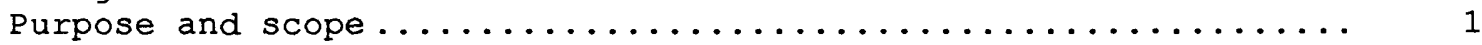

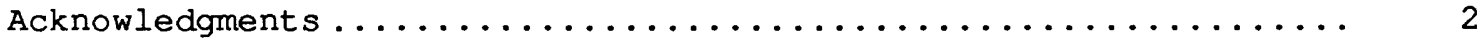

Well documentation and selection $\ldots \ldots \ldots \ldots \ldots$

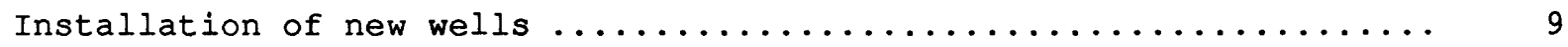

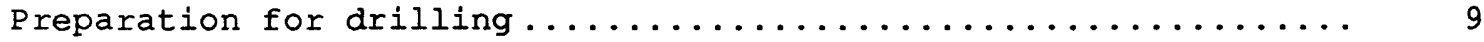

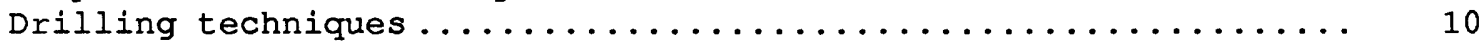

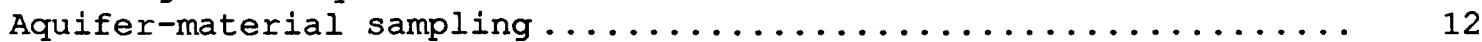

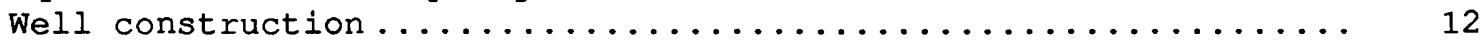

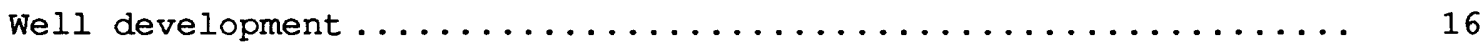

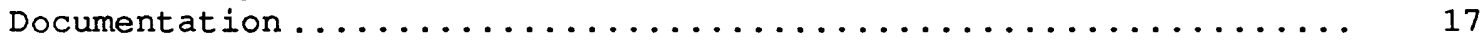

Determination of hydraulic properties .......................

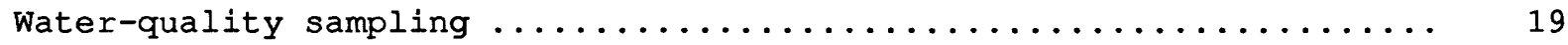

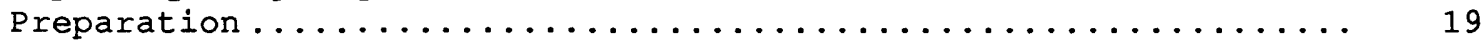

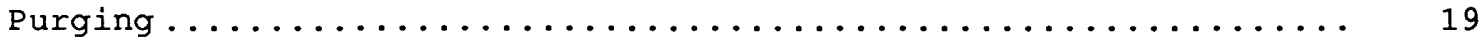

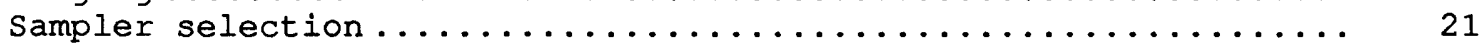

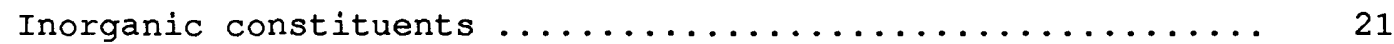

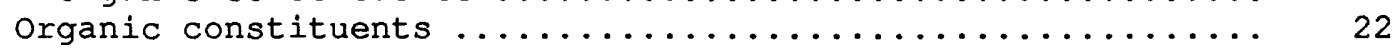

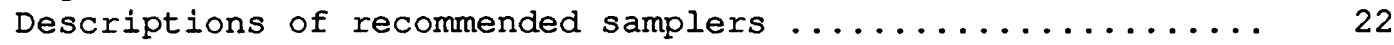

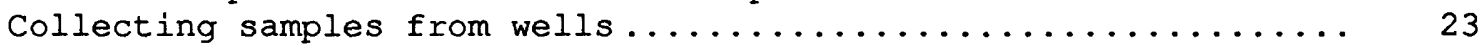

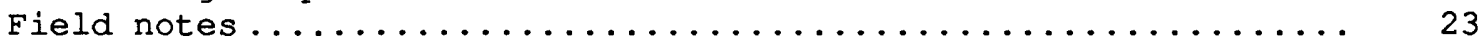

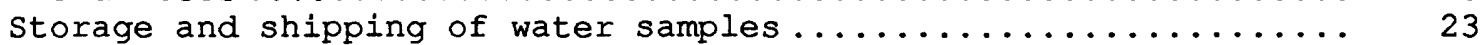

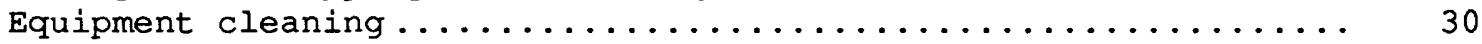

Project-submitted quality-assurance samples ................ 30

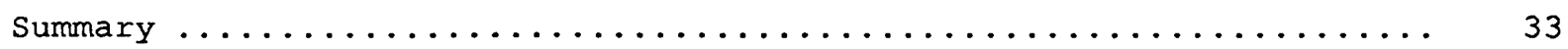

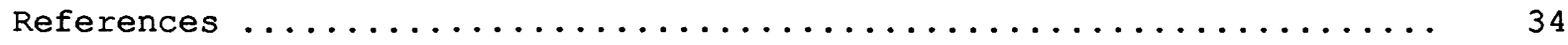

\section{ILLUSTRATIONS}

Figure 1. Land-use and land-cover field sheet, pilot National Water-Quality Assessment Program ........... 6

2. U.S. Geological Survey National Water-Quality Laboratory

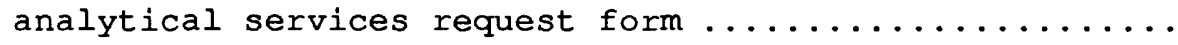


Table 1. Site characteristics recorded in the Ground-Water Site-Inventory File to extent possible at all

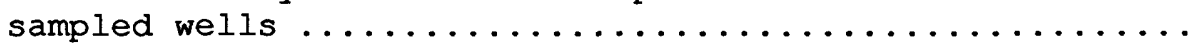

2. Site characteristics that will be recorded in the Geological Survey water-Quality File each time a

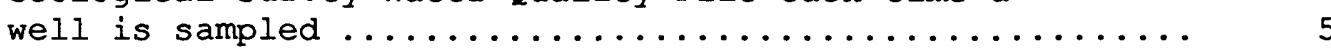

3. Advantages and disadvantages of hollow-stem augering ...... 11

4. Fitting types for well casing .................. 13

5. Decontamination solutions ..................... 14

6. Grouting materials for monitoring wells ............. 15

7. Water-quality constituents to be included in laboratory analyses for all three ground-water pilot projects, National Water-Quality Assessment Program ...........

8. General ground-water sample collection, treatment, and preservation procedures for the pilot National

Water-Quality Assessment (NAWQA) Program ........... 26

9. Suggested overall distribution of quality-assurance samples submitted by the ground-water pilot projects to the National Water-Quality Laboratory .............

\section{METRIC CONVERSION TABLE}

For the use of readers who prefer to use metric units (International System), conversion factors for inch-pound units used in this report are listed below.

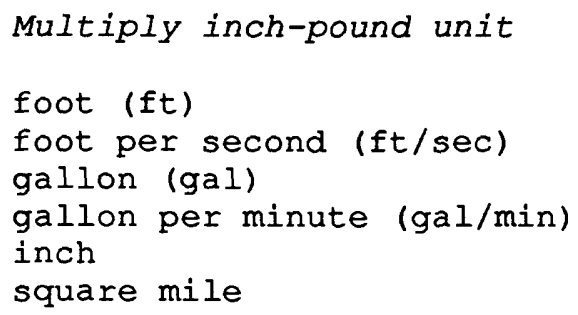

To obtain metric unit

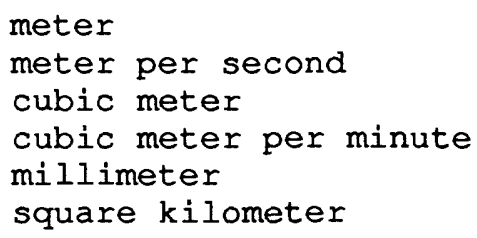




\title{
WELL INSTALLATION AND DOCUMENTATION, AND GROUND-WATER SAMPIING PROTOCOLS FOR THE PIIOT NATIONAL WATER-QUALITY ASSESSMENT PROGRAM
}

\author{
By Mark A. Hardy, P. Patrick Leahy, and William M. Alley
}

\begin{abstract}
The U.S. Geological Survey is currently (1989) undertaking a pilot National Water-Quality Assessment Program. The purpose of the pilot program is to test and refine concepts for a possible full-scale National WaterQuality Assessment Program that would provide a consistent description of the current status and trends in water quality across the Nation and insight into the major human and natural factors that control water quality in different regions. Seven pilot project areas are included in the pilot program; four focus on surface water and three focus on ground water.

This report presents criteria that are generally applicable for the conduct of ground-water field activities in the pilot project areas. Consistent criteria are described for selecting and documenting wells, installing new wells, and sampling from wells for selected water-quality constituents.
\end{abstract}

\section{INTRODUCTION}

\section{Background}

Beginning in 1986, the Congress annually has appropriated funds for the U.S. Geological Survey to test and refine concepts for a National WaterQuality Assessment (NAWQA) Program. The long-term goals of the program are to describe the status and trends in the quality of the Nation's surfaceand ground-water resources and to provide a sound, scientific understanding of the primary natural and human factors affecting the quality of these resources.

The NAWQA Program is organized into study units on the basis of known hydrologic systems (major river basins and large parts of aquifers or aquifer systems). The study units are large, involving areas of a few thousand to several tens of thousands of square miles.

At present (1989), the assessment program is in a pilot phase. Seven project areas, representing a diversity of hydrologic environments and water-quality conditions, were selected for the pilot program. The seven pilot project areas include four that focus primarily on surface water and three that focus primarily on ground water. The surface-water pilot project areas are the lower Kansas River basin in Kansas and Nebraska; the Kentucky River basin in Kentucky; the Upper Illinois River basin in Illinois, Indiana, and Wisconsin; and the Yakima River basin in Washington. The ground-water pilot project areas are the Carson River basin in Nevada and California; the Central Oklahoma aquifer in Oklahoma; and the Delmarva Peninsula in Delaware, Maryland, and Virginia.

\section{Purpose and scope}

The purpose of this report is to describe criteria that will be used in the pilot NAWQA Program for selecting and documenting characteristics 
of wells, installing new wells, and sampling from wells for selected waterquality constituents. The scope of this report includes only those guidelines that are generally applicable to all three ground-water pilot projects. Special field procedures required for the unique hydrogeologic settings and water-quality issues of particular projects are documented separately in reports that result from those projects. For example, sampling procedures described in this report apply only to those waterquality constituents analyzed in samples from all three projects.

Alternative sampling procedures may be required for constituents unique to each project.

This document has a specific purpose and scope related to the pilot NAWQA Program and is not a general purpose field manual. The report provides criteria that will ensure that comparable data are collected in the pilot program. Ultimately, these data will be used for accomplishing the long-term goals of the proposed full-scale NAWQA Program. The report supplements (1) a report that describes the concepts for a NAWQA Program (Hirsch and others, 1988), (2) a quality-assurance plan for the pilot NAWQA Program (Mattraw and others, 1989), and (3) both published technical documents (for example, Wood, 1976; Claassen, 1982; Shuter and Teasdale, 1989) of the Geological Survey and internal technical memorandums relating to field techniques.

\section{Acknowledgments}

Members of the three ground-water pilot projects contributed greatly to the development of this report. In particular, L. Joseph Bachman, David L. Parkhurst, and Alan $\mathrm{H}$. Welch provided initial written comments on proposed field procedures for the projects and provided many insightful comments during the development of this report. Michael T. Koterba and Mark W. Sandstrom provided valuable comments on sampling and quality assurance. Elizabeth $A$. Frick helped to design the land-use and land-cover field sheet.

\section{WELL DOCUMENTATION AND SELECTION}

Both existing wells and newly constructed wells will be sampled as part of the NAWQA pilot projects. A general policy of the pilot NAWQA Program is to sample only from those existing wells for which information on well construction and the local hydrogeology is sufficient to (1) determine the hydrogeologic unit from which the well is producing, and (2) assure that the well is suitable for sampling the constituents of concern. In particular, this includes information on the depth of the well, depth to the top and bottom of each open interval, the hydrogeologic unit(s) to which the well is open, the casing type, and the pump type. In some instances, these characteristics will not be known completely for all wells that are candidates for sampling. Dependent on the situation, the most suitable of the candidate wells will be selected for sampling, or a new well will be constructed.

In general, wells selected as potential sampling sites will be visited prior to sampling, and the existing data for these wells will be field checked and verified to the extent possible. A sampling network that meets the program objectives will be selected from this group of wells.

Wells that are sampled need to be located accurately. Determining the location of wells will be accomplished primarily by computing latitude and longitude from Geological Survey 7 1/2-minute quadrangle maps. This 
procedure generally is considered to be accurate to the nearest 5 seconds. Public land system (PLS) coordinates will be used, where available, in addition to latitude and longitude. In instances when greater accuracy in location is needed, horizontal and vertical control will be determined by standard second-order surveying techniques (Davis and others, 1966, p. 887).

Two forms will be used to record information on wells. Site schedules in common use by individual Geological Survey offices will be used to collect data that will be stored in the Geological Survey Ground-Water SiteInventory (GWSI) File. In addition, a land-use and land-cover field sheet developed specifically for the pilot NAWQA Program will be used.

In general, as much well construction information as possible will be obtained and recorded on the appropriate site schedule form. Table 1 lists site characteristics that will be emphasized on the site schedule form. This information may help resolve questions concerning sampling results and their interpretation. It is important to have accurate data on the well's construction, because the construction affects the hydrogeologic units from which the well is producing and may influence the composition of water withdrawn from the well. The well construction also determines the type of equipment needed to sample the well.

Well information can be derived from a number of sources including data files maintained by the U.S. Geological Survey, State, and local agencies; the well driller; and possibly the well owner. Data on well construction often will come from available records. However, during the preliminary site visit, additional data on well construction frequently will be collected and available data verified to the extent possible.

In addition to the data stored in GWSI, table 2 lists four characteristics that will be recorded in the U.S. Geological Survey Water-Quality File each time a well is sampled. This information includes the purpose for sampling the well and the sampling method.

The land-use and land-cover field sheet is shown in figure 1 . The purpose of the field sheet is to document land use and land cover in the vicinity of each well. This information will be used to help explain waterquality sampling results.

The field sheet is to be completed in its entirety the first time a well is sampled. The field sheet for a well then will be checked each subsequent time a well is sampled and any changes noted on a new sheet. A special computer file has been developed for the pilot NAWQA Program to store information from the land-use and land-cover field sheets (Jonathan $C$. Scott, U.S. Geological Survey, written commun., 1989).

In addition to completing the land-use and land-cover field sheet, the following photographs generally will be taken at each well: (1) One photograph of the well and surrounding area as seen when approaching the well; (2) one closeup photograph of the well and water-level measuring point; (3) four photographs that show the area near the well (These photographs will be taken to the north, east, south, and west. After the film has been developed, the direction of the photographs from the well will be clearly labeled); and (4) any number of additional photographs to document features that could influence the quality of water at the well.

Special care will be taken to identify on the photograph the measuring point used for water-level measurements and the sampling point used for 
Table 1.--Site characteristics recorded in the Ground-Water Site-Inventory File to extent possible at all sampled wells

Code Site characteristic

\begin{tabular}{|c|c|}
\hline $\mathrm{C} 1$ & Site ID (station number) \\
\hline $\mathrm{C} 2$ & Type of site \\
\hline c3 & Data reliability \\
\hline C4 & Agency code \\
\hline C5 & Project number \\
\hline c6 & District code \\
\hline C7 & State code \\
\hline C8 & County code \\
\hline C9 & Latitude \\
\hline $\mathrm{C} 10$ & Longitude \\
\hline C11 & Latitude-longitude accuracy code \\
\hline $\mathrm{C} 12$ & Local well number \\
\hline $\mathrm{C} 16$ & Altitude of land surface, in feet \\
\hline C17 & Method used to determine altitude \\
\hline $\mathrm{C} 18$ & Accuracy of altitude \\
\hline C19 & Topographic setting \\
\hline C23 & Primary use of site \\
\hline $\mathrm{C} 24$ & Primary use of water \\
\hline $\mathrm{C} 28$ & Depth of well, in feet \\
\hline C29 & Source of depth data \\
\hline C43 & Type of lift \\
\hline $\mathrm{C} 60$ & Date of well construction \\
\hline $\mathrm{c} 65$ & Method of construction \\
\hline c66 & Type of finish \\
\hline C67 & Type of surface seal \\
\hline $\mathrm{C} 80$ & Casing material \\
\hline $\mathrm{C} 83$ & Depth to top of open interval, in feet (for each open interval) \\
\hline C84 & Depth to bottom of open interval, in feet (for each open interval) \\
\hline C91 & Depth to top of geohydrologic unit, in feet (for each unit) \\
\hline C92 & Depth to bottom of geohydrologic unit, in feet (for each unit) \\
\hline C93 & Lithologic unit identifier (for each unit) \\
\hline C161 & Well owner \\
\hline C235 & Date water level measured \\
\hline C237 & Water level, in feet below land surface \\
\hline $\mathrm{C} 238$ & Status of well at time of water-level measurement \\
\hline $\mathrm{C} 239$ & Method used to measure water level \\
\hline C268 & Rated capacity of pump, in gal/min \\
\hline C276 & Accuracy of water-level measurement \\
\hline C321 & Begin data for use of water-level measuring point \\
\hline C322 & End data for use of water-level measuring point \\
\hline C323 & Height of water-level measuring point \\
\hline C324 & Description of water-level measuring point \\
\hline C713 & Aquifer-type code \\
\hline C714 & Primary aquifer \\
\hline
\end{tabular}


Table 2.--Site characteristics that will be recorded in the Geological Survey Water-Quality File each time a well is sampled

Code Site characteristic

71999

Sample purpose code

(Record a value of 15 to indicate that this sample was collected as part of the National

Water-Quality Assessment Program)

84144

Well-selection criteria

100 - Well selected for sampling because site is near or within a known or suspected local problem area.

200 - Well selected for sampling primarily without regard to any known or suspected local problem areas.

84145

Project component

100 - Regional or survey sampling

200 - Targeted sampling (Agricultural area)

300 - Targeted sampling (Urban or suburban area)

400 - Targeted sampling (Naturally occurring substances)

500 - Targeted sampling (Local-scale network)

600 - Targeted sampling (Other)

700 - Geochemical investigation

Sampler type

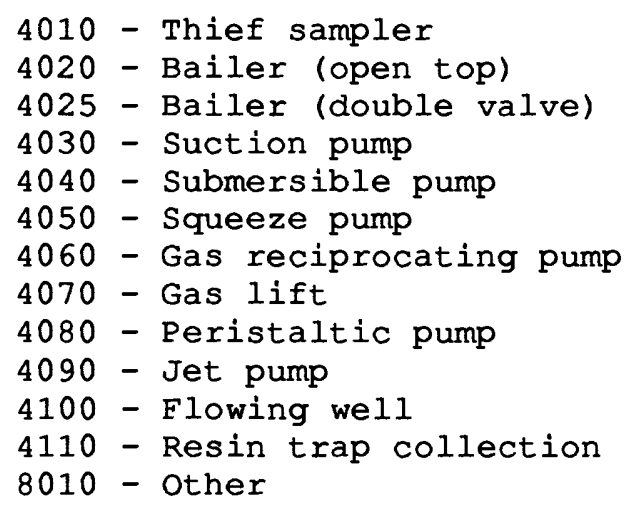


LAND USE AND LAND COVER FIELD SHEET - GROUND-WATER MAWOA PILOT STUDIES

DATE FIELD CHECK

WELL STATION ID

LOCAL NUMBER

- PERSON CONDUCTING FIELD

1. TOPOGRAPHIC SETTING OF WELL (a) or marsh; mangrove swamp; of fshore (estuary); pediment; hillside (slope); alluvial or chap. II, P. B-19)

2. LAND USE AND LAND COVER CLASSIFICATION - (modified from Anderson and others, 1976, p. 8) Check all land uses that occur within each approximate distance range from the sampled well. Identify the predominant land use within each distance range and estimate its percent of the total area $(0-25,26-50,51 \cdot 75$, or $76-100 \%)$ within a $1 / 4$ mile radius of the well.

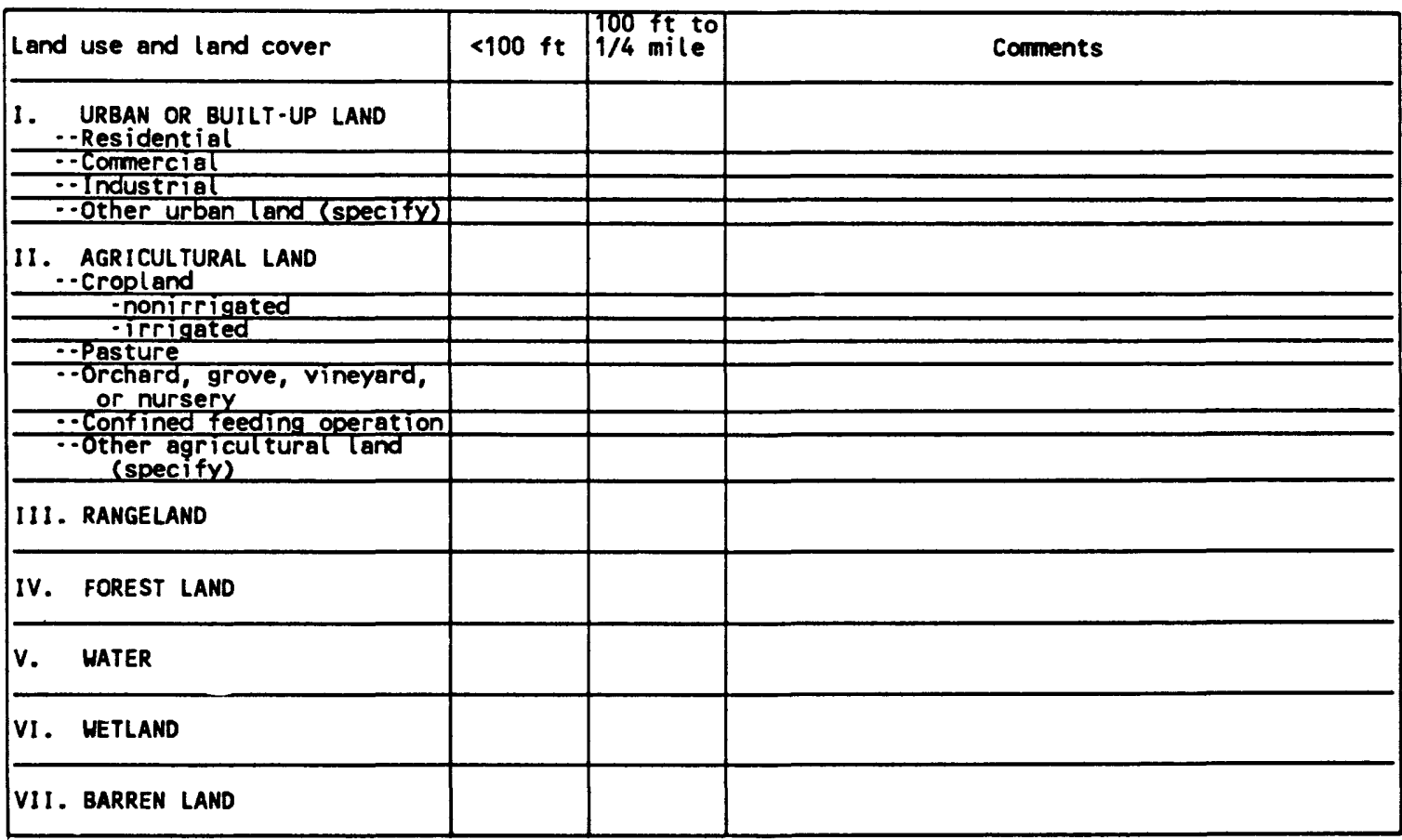

3. AGRICULTURAL PRACTICES - Describe agricultural practices within $1 / 4$ mile of the sampled well.

a. EXTENT OF IRRIGATION - Circle applicable statement.

nonirrigated, supplemental irrigation in dry years only, irrigated

b. METHOD OF IRRIGATION - Circle those that apply.

spray, flood, furrow, drip, chemigation, other (specify)

c. SOURCE OF IRRIGATION WATER - Circle those that apply.

Ground water, surface water, spring, sewage effluent (primary, secondary, or tertiary treatment)

d. PESTICIDE AND FERTILIZER APPLICATION - Provide information about present and past pesticides and fertilizers used, application rates, and application methods.

e. CROP AND ANIMAL TYPES - Provide information about present and past crop and animal types, and crop rotation practices.

Figure 1.--Land-use and land-cover field sheet, pilot National Water-Quality Assessment Program 
LAND USE AND LAND COVER FIELD SHEET - GROUND-MATER NAMRA PILOT STUDIES

page $2(07 / 88)$

4. LOCAL FEATURES - Check all local features that may affect ground-water quality which occur within each approximate distance range from the sampled well.

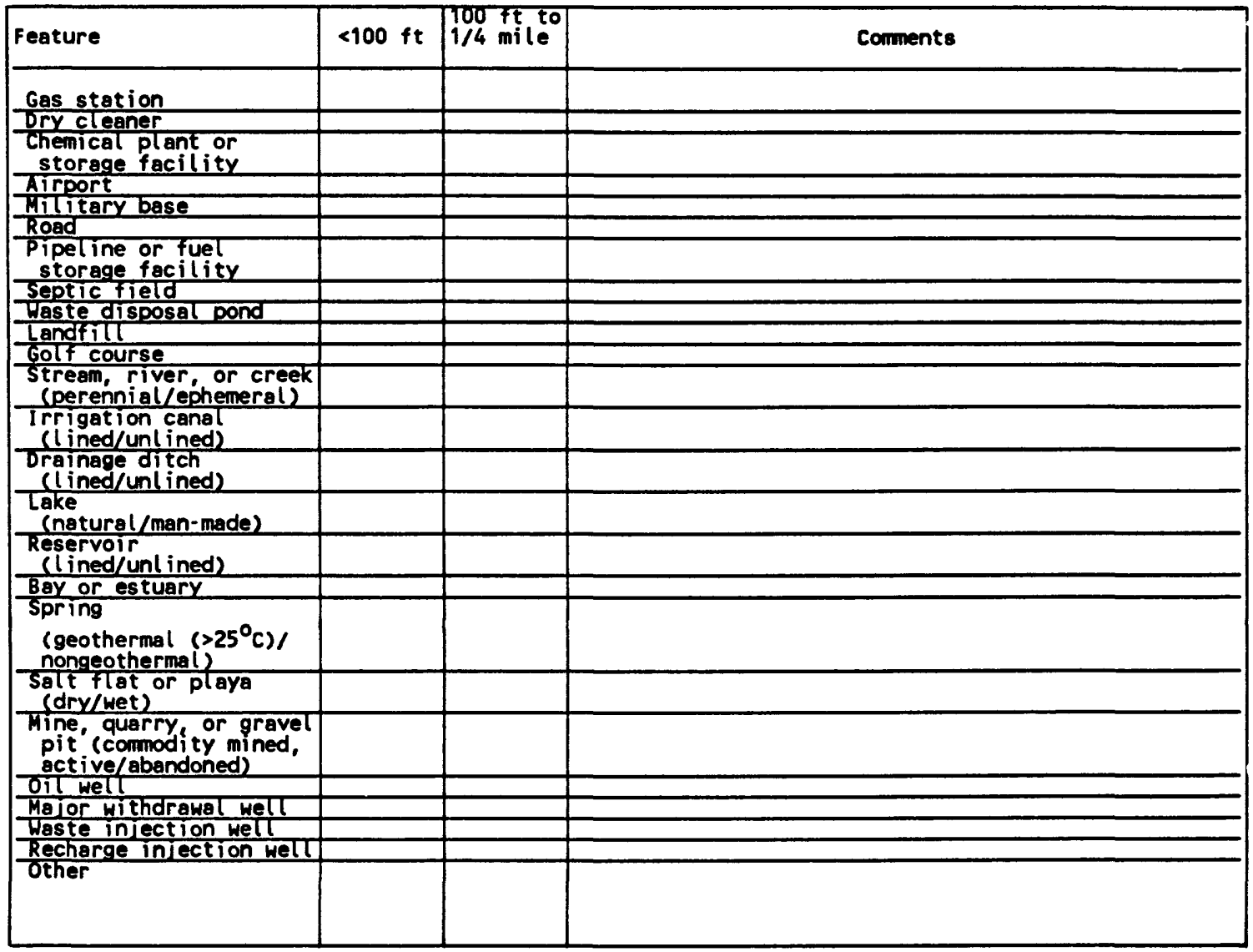

5. LAND-USE CHANGES - Have there been major changes in the last 10 years in land use within $1 / 4$ mile of the sampled well? Yes_Probably_ Probably not_ No_ If yes, describe major changes.

6. ADDITIONAL COMMENTS - Emphasize factors that might influence local ground-water quality.

Figure 1.--Land-use and land-cover field sheet, pilot National Water-Quality Assessment Program--Continued 
production wells. In some cases, these photographs may help in locating the site at a later date. The date the photograph was taken will be marked on the back of each photograph. The photographs, which will be a record of current land use near the well, may be useful in defining changes in land use that have occurred between sampling periods. These photographs and the land-use and land-cover field sheet for each sampling site will be stored in the local Geological Survey office site schedule file.

Information pertaining to the accessibility of the site also will be documented in the site schedule file. Examples of pertinent information include the site owner, contacts necessary for permission to sample, special constraints that may affect when the well can be sampled, and procedures needed to gain access to the well. Whenever possible, wells that have the potential for long-term access will be selected as sampling wells.

Observation and production wells will be included in the sampling network. In contrast to observation wells, production wells have the advantage of yielding large volumes of water and having pumping equipment in place. However, there are distinct disadvantages to production wells. For example, (1) the existing pumping equipment may affect water quality, (2) certain well construction features may not be desirable, and (3) access for sampling and water-level measurement may be difficult. The impact of each of these three factors is discussed below.

The type of pumping equipment may affect the suitability of water samples for some chemical analyses. For example, oil-lubricated pumps may contaminate samples that are collected for analysis of some organic constituents. For this reason, older turbine pumps, which commonly are oil-lubricated, will be avoided when sampling for organic compounds. In addition, wells that cavitate during pumping may affect the chemistry of the water withdrawn and will be avoided.

Well construction features of production wells also may affect the water quality. For example, if threaded steel casing and couplings were used, it is probable that the threads were coated with grease prior to installation. This grease is a potential contaminant to samples collected for some organic analyses. Also, the location of the pump intake is important in terms of purging the well prior to sampling.

Wells that are screened or open to more than one interval will be avoided, to the extent possible, because of uncertainties concerning the source of the sampled water. However, if a multi-screened well is the only available well within an area of interest, it may be necessary to include it in the sampling network to insure adequate spatial coverage. If the screened or open intervals are within the same aquifer, this problem is less of a concern than if the screened or open intervals are in multiple aquifers.

It is also important to consider the borehole hydraulics of a well prior to purging and sampling. Reilly and others (1989) have shown that observation wells with long screens in some hydrogeologic settings may have substantial well-bore flow. Sites where this natural flow within the borehole may be substantial should be avoided; instead, wells with a short screen or open interval should be selected for sampling.

In addition to the screened or open interval of a well, the location of the gravel pack may have a major influence on the hydrogeologic units from which the well is producing. Many wells have short screens or open 
intervals but are gravel packed from the bottom of the well to the base of the seal, several feet below the land surface. Other factors constant, wells with short gravel-packed intervals generally are preferred.

The accessibility of a sampling point is an important consideration in selecting a production well for sampling. Most wells will have an access point that can be identified during a field check prior to sampling. This access point should be located as near as possible to the wellhead, before on-site treatment, a pressure tank, or a holding tank.

Finally, certain criteria for well selection will arise from the specific objectives for a given well network. For example, potential sites that have a complex mix of land uses should be avoided for special studies of the effects of land use on ground-water quality because interpretation of the data would be difficult.

\section{INSTALLATION OF NEW WELLS}

Some wells will be installed by the pilot project teams to sample shallow ground water (generally to depths less than 50 feet). The installation of these wells will involve the selection of techniques for drilling, coring and sampling, and related items. The selection of the best suited techniques is important for the NAWQA pilot studies to ensure the collection of representative water-quality data. Shuter and Teasdale (1989) discuss in detail a number of techniques for drilling, coring and sampling, and well development for test holes and wells.

Depending on the drilling capabilities available to each pilot project, drilling services may be contracted for the installation of these wells. The type of well installation provided by contractors will depend on local industry standards in each pilot project area. The pilot project staffs will evaluate the types of well construction available and select the best techniques. Contracts will be prepared that will specify drilling or augering techniques that minimize the introduction of drilling fluids into the ground-water system. The following are general guidelines for well installation.

\section{Preparation for Drilling}

When sites are selected for potential well installation:

(1) Make site visit to assess conditions;

(2) Acquire necessary well drilling permits and approvals from the site owner and Federal, State, and local regulatory authorities;

(3) Establish utility clearances. A commercial line-locating service may be used for this purpose. However, this service usually covers only transcontinental gas pipelines, phone utility lines, and electric utility lines. Local sewer lines, water lines, and in some cases, site specific electrical service must be located in coordination with local authorities or property owners; and

(4) At a minimum, meet all local, State, and Federal regulations governing well drilling activities. 
Numerous techniques can be used to install shallow wells. Those techniques that will be used by the NAWQA pilot projects are (1) hollowstem continuous flight augering, (2) solid-stem continuous-flight augering, (3) rotary drilling, and (4) for very shallow depths, use of a soil auger to drill a pilot hole followed by installation of casing driven by hand.

All drilling methods have disadvantages for ground-water monitoring. For example, some of the advantages and disadvantages of hollow-stem augering are enumerated in table 3. Hollow-stem augering has several advantages, including coring capabilities. One problem with the use of augers is that cross contamination can occur as cuttings are rotated upwards on the auger flights. Keely and Boateng (1987a, 1987b) present a method to decrease the effects of this problem. Their approach involves driving a temporary casing to shield one stratum from another.

Solid-stem augering has the potential for caving problems during coring and casing. If solid-stem augering is used and caving is a problem, one solution may be to auger to the top of the saturated zone and then drive casing several feet (ideally at least 5 feet) into the saturated zone.

Rotary drilling generally will be avoided for wells sampled for trace organic compounds. When rotary drilling is used, the casing of the completed well should be at least 4 inches in diameter to allow for proper development of fines in the aquifer material surrounding the screen. The drilling mud, if used, should be specified as sodium bentonite, free of added organic materials. Concerns about using drilling mud include the potential for cross-contamination of strata exposed to circulating mud in the borehole and the potential introduction of oils and other contaminants by the mud pump. Compressed air (air-rotary drilling) may be used rather than mud to cool the drill bit and to remove cuttings from the borehole. However, unless the air is filtered, oils and other contaminants may be introduced into the borehole from the air compressor (Keely and Boateng, 1987a). In addition, the introduction of air may result in chemical changes in the aquifer water and require extensive well development prior to sampling. Additives sometimes used in air rotary drilling will be avoided when drilling wells.

Flights, drill rods, bits, and core barrels will be washed with clean water before beginning augering or drilling; they will be steam cleaned if obvious contaminants were encountered or suspected in the soil or aquifer materials at the previous site. The augering and drilling equipment will be visually inspected for hydraulic fluid leaks, as these are potential sources of contamination. Also, Teflon 1 tape will be used as needed on couplings for drill rods, bits, and core barrels. Nonpetroleum based lubricants and pure petroleum jelly can be used for this purpose but are less desirable.

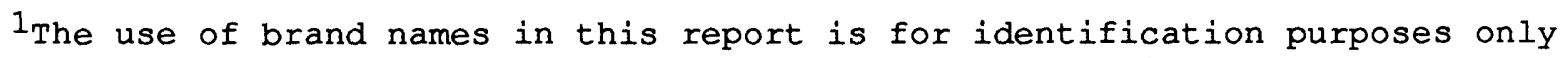
and does not constitute endorsement by the U.S. Geological Survey.
} 
Table 3.--Advantages and disadvantages of hollow-stem augering

[Modified from Gillham and others, 1983]

\section{Advantages}

Disadvantages

- Can avoid the use of foreign

- Can cause vertical mixing of fluids. formation water and geologic materials.

- Can avoid the use of lubricants.

- Suitable for collecting geologic

- Possible contamination from samples. metal components.

- Limited to unconsolidated

- Water samples can be collected. during drilling. geologic materials without large rocks.

- Sand packs and seals can be positioned accurately.

- Limited to depths of about 30-50 meters (100-165 feet).

- Relatively inexpensive.

- Auger rigs are mobile and are readily available.

- Unconsolidated materials may surge into the hollow stem preventing desired placement of screens. 


\section{Aquifer-Material Sampling}

Core samples often will be collected for analysis of the aquifer material. In general, this involves driving a sampling tube in advance of the drill bit. Commonly used coring devices are the split-spoon sampler and the shelby tube. These samplers can be used with both hollow-stem and solid-stem augers. In general, the split-spoon sampler is used in unconsolidated material where large-size fragments of rock are not present. One advantage of the shelby tube is that the resulting core can be used for the extraction of pore water and for other hydraulic analyses. Cores of near-surface materials $(0-20 \mathrm{ft})$ may also be taken using a vibra-corer (Finkelstein and Prins, 1981). The vibracorer produces a continuous core with minimal disturbance of layered and bedded structures.

\section{Well Construction}

Well construction includes selecting casing materials and using appropriate techniques for sealing the annular space surrounding the casing. National Sanitary Foundation (NSF) approved PVC casing will be used, particularly schedule 40 flush-threaded casing. In certain situations, the stronger schedule 80 casing will be used. Advantages and disadvantages of different types of casing couplings are presented in table 4. If shallow wells need to be driven by hand, stainless steel casing is appropriate. Either 2-inch- or 4-inch-diameter casing will be used. The 4-inch casing is recommended, because it easily accommodates pumps and water-level recorders. Well screens will be made of PVC or stainless steel and typically will be 3 to 5 feet in length. In consolidated aquifer material, a 10-foot slotted pipe or open hole may be used instead of a well screen. The slot size will be selected based on the grain size of the aquifer material (Driscoll, 1986, p. 435-438). Where this approach is impractical, the slot size will be determined by a review of well construction records for nearby wells or by general knowledge of the area.

In general, the top of the well screen will be placed at least 5 feet below the average water-table altitude to reduce the probability that the well will be dry during parts of the year. However, for some special investigations, the well screens may be finished closer to the water table. Seasonal fluctuations at nearby observation wells will be examined, as needed, to determine the placement of well screens.

Prior to the installation of casing and screen, the materials should be in a contamination-free condition. A detergent wash is generally required. Steam cleaning or a high-pressure water spraying technique with low sudsing soap or detergent is preferable (Richter and Collentine, 1983). Table 5 lists some decontamination solutions. As an alternative to washing, casing can be purchased that is precleaned and wrapped in plastic. This approach eliminates the need for cleaning, but the casing is more costly.

The wells will be completed by grouting and sealing. A comparison of grouting materials is presented in table 6. Guidelines for completing wells are as follows. Backfill with a well sorted, washed sand opposite the screen. This sand pack shall consist mainly of quartz, contain no limestone or other calcareous material, such as shell fragments, and contain no organic material such as wood fragments or lignite. The particle size of the pack shall be consistent with the prevailing grain size of the aquifer material. A 1 -foot plug of fine-grained quartz sand should be placed above the sand pack. This plug will prevent the seal material from infiltrating the pack. If installation of this plug is impractical, the 


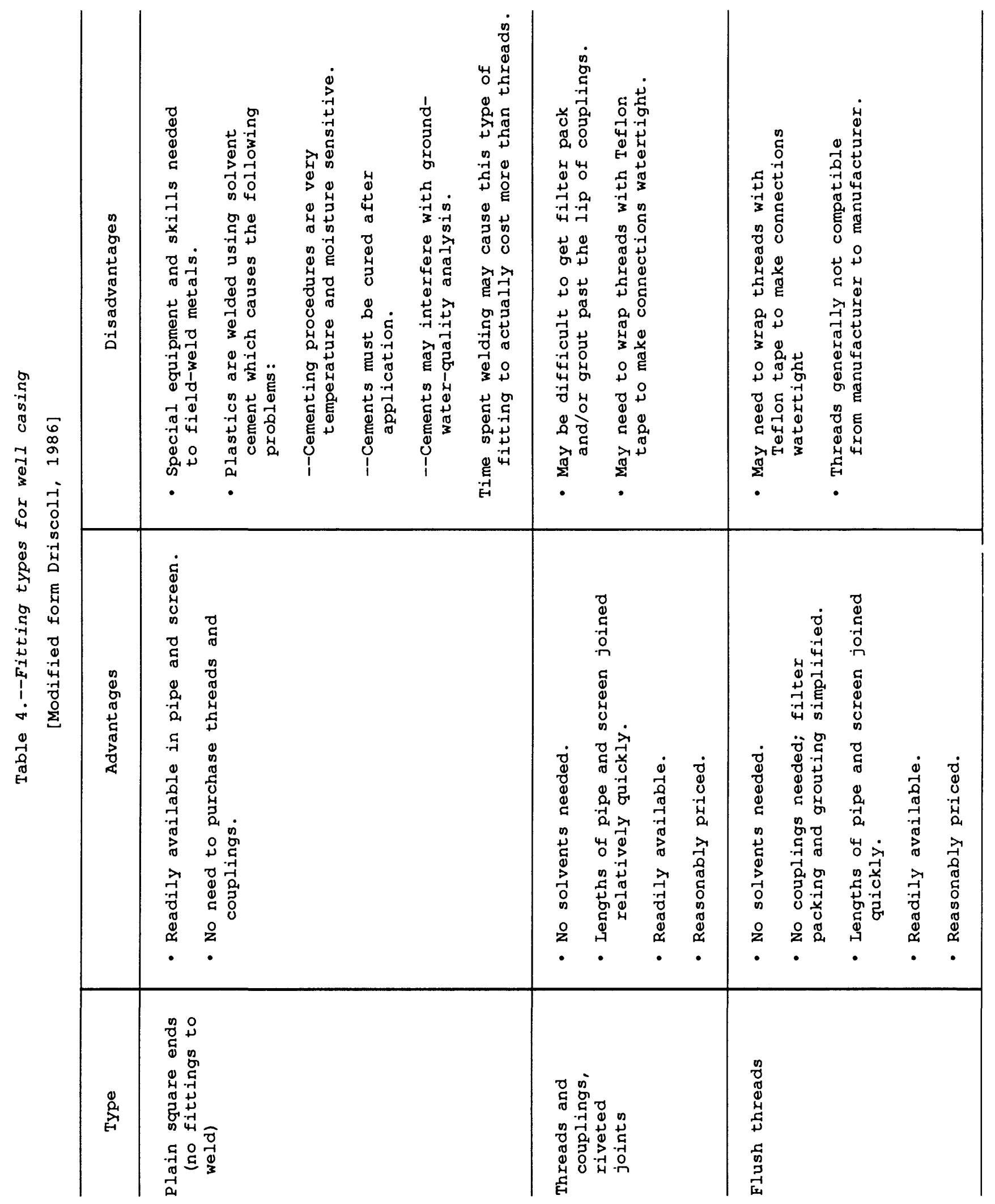


Table 5.--Decontamination solutions

[Modified from Richter and Collentine, 1983]

Name of solution

Sodium bicarbonate

Sodium carbonate

Trisodium phosphate

Calcium hypochlorite
Remarks

Effective for acids and bases, amphoteric, 5-15 percent aqueous solution.

Effective for inorganic acids, good water softener, 10-20 percent aqueous solution.

Good rinsing solution or detergent, 10 percent aqueous solution.

Excellent disinfectant, bleaching and oxidizing agent, 10 percent aqueous solution. 


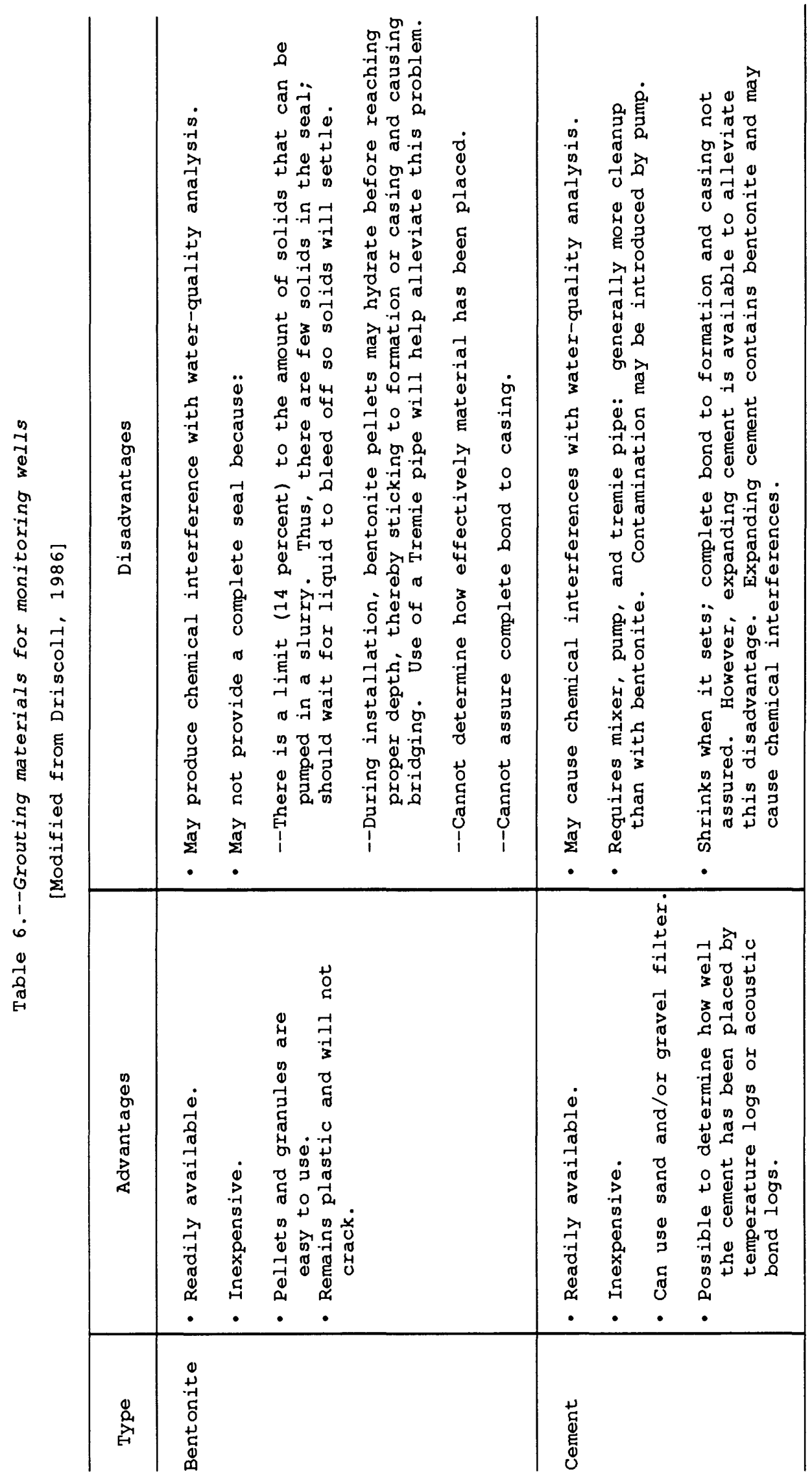


sand pack should extend 5 to 10 feet above the top of the screen. However, the sand pack should not cross any confining units, thereby allowing flow from multiple aquifers to the well. The remainder of the annular space should be filled with bentonite or native sediment. Bentonite generally is preferred over native sediment to minimize contamination due to flow in the well's annular space. Cement may be used instead of bentonite in areas where high sulfate or saline waters are present. If native sediment is used to fill the annular space, a plug of at least 5 to 10 feet of bentonite should be placed on the sand pack or plug of fine-grained sediment. Bentonite is available in powder, granular, and pellet form. Granules generally will be used for the relatively shallow wells installed by the projects. The seal shall begin at the top of the 1-foot plug or sand pack and progress upward to within the depth affected by frost or within 3 feet of the land surface, so as to insure a continuous, effective seal. The uppermost part of the annular space will be filled with expanding cement within the depth affected by frost or as acceptable to local regulatory agencies.

As needed, a surface casing of steel will be installed at a height of about 4 feet to protect the well and to provide a base for possible waterlevel recorders. At some sites, it may be necessary to finish the well at or below the land surface. These wells will be designed, as needed, with watertight plugs or caps to prevent the entry of surface runoff to the well. At these sites, temporary shelters will be designed for any water-level recorders in use.

\section{Well Development}

During well development, the mud cake produced by the drilling process is cleaned off, and the small-sized particles are removed from the well. The procedure permits ground water to flow more easily into the well and helps to provide water free of suspended solids for sampling. The following techniques can be used for well development:

Surge block - A surge block slightly smaller in diameter than the well casing can be hand operated to depths of 40 to 60 feet. Caution must be used so as to not damage the well and screen.

Bailing - Although bailing is less effective than the surge block technique, the potential for well damage is minimal.

Surging by pumping - Recurrent pumping surges the well through cycles of drawdown and recovery. Generally air is used for pumping, however, which may change the chemistry of the ground water. Also, the procedure may be a potential source of contamination from lubricating oils. In shallow wells, a water-lubricated pump can be used for well development. This procedure has little effect on the chemistry of the ground water.

High velocity jetting - Either air or water in combination with air-lift pumping can be used to surge the well. The major benefit of this technique is that the jetting is done directly on the well screen. This method generally is regarded as one of the most effective well-development methods (Driscoll, 1986). However, the technique introduces air or water into the well and may change the chemistry of the ground water. 
Indirect eduction jetting (IEJ) - An eduction line (rigid pipe or flexible tubing) about $1 / 2$ the diameter of the well is placed to the depth of the center of the screen, and an air line is placed inside the eduction line about $1 / 3$ the length of the static water column above the screen. Air is pumped to surge the well and the well discharges through the eduction line. The benefit of this technique is that air is not introduced into the aquifer. Therefore, the procedure has little effect on the chemistry of the ground water.

Brushing - Screens obstructed by sediment in shallow, small diameter wells can sometimes be dislodged by brushing. A long-handled brush with stiff bristles may be used to gently brush the screened interval.

\section{Documentation}

It is important to document the installation of wells. This documentation will include:

(1) Lithologic logs;

(2) Geophysical logs, as appropriate;

(3) Well construction diagram or equivalent field notes indicating depth, screen interval, and other important construction details;

(4) GWSI form and land-use and land-cover field sheet;

(5) Location - The location information should be cross-referenced with State identifications, U.S. Environmental Protection Agency identifications, and other location systems;

(6) Results of core analyses and hydraulic testing;

(7) Miscellaneous information--for example, bentonite lot numbers; and

(8) Photographs.

\section{DETERMINATION OF HYDRAULIC PRORERTIES}

Hydraulic properties of aquifers and confining units in the vicinity of wells can be estimated using several techniques: (1) interpretation of geophysical and lithologic logs, (2) hydraulic analysis of core samples, (3) estimates from measured specific capacities, (4) aquifer-test analysis, and (5) regional simulation of ground-water flow. Each method has an inherent range of uncertainty and certain benefits and limitations dependent on the level of complexity associated with the technique and the amount of data needed to accurately apply the technique.

The pilot projects will, in some cases, be determining hydraulic properties of aquifers and confining units in the vicinity of wells, but also will be using values determined by others. It is important to understand the limitations of various methods.

The least complex, but most uncertain, approach used to define hydraulic properties is to estimate them from lithologic or geophysical 
logs. This technique involves assigning a value of hydraulic conductivity based on a physical description of the aquifer material from lithologic logs or from an analysis of borehole geophysical logs. The method is explained in detail in Lohman (1972, p. 53). Values of hydraulic conductivity, porosity, and specific yield for selected rocks are given in Heath (1983) and Wolff (1982).

Hydraulic analysis of core samples can be used to define hydraulic properties. Limitations of this approach are that (1) the properties reflect only a small sample interval (the size of the core) and may not reflect an areally effective value for the hydrogeologic system, and (2) it is difficult to extract an undisturbed core that reflects in situ conditions. Numerous geotechnical laboratories routinely conduct tests to define hydraulic conductivity and compressibility. Freeze and Cherry (1979, p. 335-339) describe the laboratory tests commonly used to determine hydraulic properties.

Specific capacity data (the ratio of well discharge to drawdown) can be used to estimate hydraulic conductivity or transmissivity, but not storage properties. McClymonds and Franke (1972) and Hurr (1966) describe techniques for estimating transmissivity from specific capacity.

An aquifer test is a controlled field experiment specifically designed to determine the hydraulic properties of a hydrogeologic system. A test typically consists of observing water levels through space or time in response to a known hydraulic stress, generally the withdrawal of water from a well. A number of different analytical techniques can be used to analyze the aquifer-test data, dependent on the hydrogeologic setting and the design of the test. Single-well tests are used to define only hydraulic conductivity or transmissivity. An observation well usually is needed to accurately determine storage properties. Hydraulic properties determined from tests involving a pumping well and observation wells reflect a much greater areal sampling of the hydrogeologic system and, thus, are considered to be better estimates of properties that control areal ground-water flow. The U.S. Geological Survey (Office of water Data Coordination, 1977) and Stallman (1971) describe procedures and recommended methods to design, conduct, and analyze the results of an aquifer test. Additional sources of information include Lohman (1972), Freeze and Cherry (1979), Reed (1980), and Heath (1983). Bennett and Rosenshein (1984) present a series of papers that reflect the state-of-the-art of ground-water hydraulics. Topics addressed include slug tests, pumping tests in fractured rock aquifers, and analysis of tests in a variety of hydrogeologic settings.

Most analytical techniques assume that the hydraulic properties are areally homogeneous. In some instances, the data (water levels from multiple observation wells distributed both vertically and areally) are available to determine the distribution of hydraulic properties in complex hydrogeologic systems. Numerical models of ground-water flow such as presented by Reilly (1984) and McDonald and Harbaugh (1988) can be used for this purpose.

In addition, reasonable estimates of hydraulic properties on a local scale sometimes can be derived from a regional analysis of ground-water flow. Ground-water flow models have been developed and calibrated for many areas. As part of the calibration process, the areal distribution of hydraulic properties of aquifers and confining units is estimated. Those values may be used, realizing the inherent limitations associated with the simulation scale of the particular areal model, to estimate local hydraulic properties. 


\section{WATER-QUALITY SAMPIING}

\section{Preparation} sample :

The following tasks should be completed before going to a site to

(1) Obtain permission from the well owner to sample;

(2) Arrange access to the site;

(3) Complete site-descriptive information on field sheets and the National Water-Quality Laboratory analytical services request forms (see fig. 2) through record 3, except for the date and time of the sample;

(4) Clean pumps, delivery lines, and samplers; and

(5) Perform instrument maintenance and temperature calibrations on instruments.

\section{Purging}

Purging supplies aquifer water to the well by removing the water standing in the well casing. Before purging, the volume of water in the casing must be calculated (except for continuously operated production wells). In commonly used units, the volume is:

$$
\mathrm{V}=0.0408 \mathrm{HD}^{2}
$$

where $V$ is the volume of water in the casing, in gallons;

$D$ is the inside diameter of the casing, in inches; and

$\mathrm{H}$ is the length of the water column in the casing, in feet.

$\mathrm{H}$ is the difference between the depth to water and the depth of the well. If the water level in the well cannot be determined, the entire well depth will be used as the length of the water column. If possible, a static waterlevel measurement will be collected in accordance with established methods (Office of water Data Coordination, 1977, p. 2-8).

Purging ideally should be done from the top of the water column to most efficiently, eliminate standing water. This will not be possible in production wells with installed pumps. In observation wells, pumps having capacities per minute of at least 2 percent of the volume of water in the casing will be used. Smaller capacity pumps will be used only if the size of the well casing prohibits use of larger pumps. The pump intake initially will be placed below the static water level within the upper 10 percent of the total depth of water and lowered as needed to keep the intake submerged. If the well casing is entirely evacuated during purging, it will be allowed to recover sufficiently to collect a sample, or if recovery is not sufficient, the well will not be sampled.

The pumping rate and chemical stability of the discharge water will be monitored after purging is started. Flow meters can be used for monitoring pumping rate. Measuring the time required to fill a container of known volume also is adequate. 


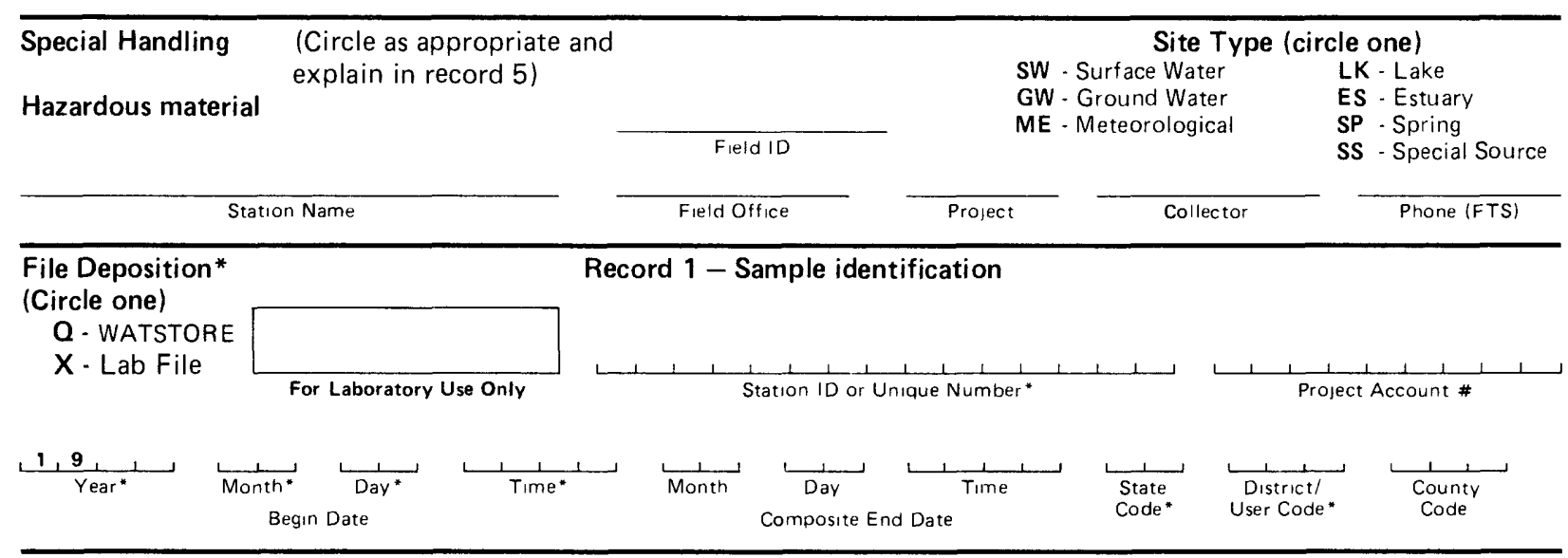

Record 2 - Analysis level codes and schedules

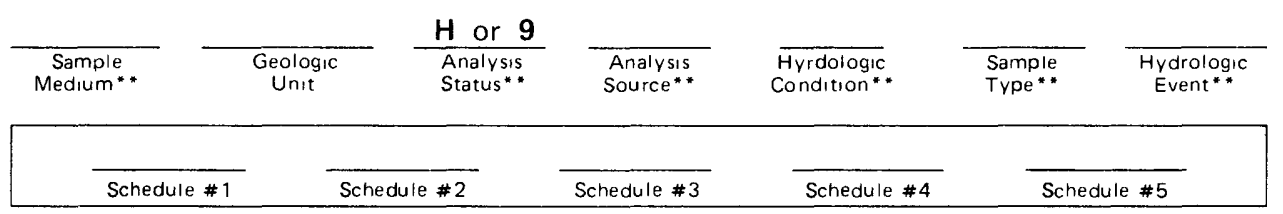

Record 3 - Laboratory codes to be added to (A) or deleted from (D) above schedules

\begin{tabular}{|c|c|c|c|c|c|c|c|c|c|c|c|c|c|c|c|}
\hline$\overline{\text { Code }}$ & $\overline{A / D}$ & $\overline{\text { Code }}$ & $\overline{A / D}$ & $\overline{\text { Code }}$ & $\overline{A / D}$ & $\overline{\text { Code }}$ & $\overline{A / D}$ & $\overline{\text { Code }}$ & $\overline{\mathrm{A} / \mathrm{D}}$ & $\overline{\text { Code }}$ & $\overline{A / D}$ & $\overline{\text { Code }}$ & $\overline{A / D}$ & $\overline{\text { Code }}$ & $\overline{A / D}$ \\
\hline$\overline{\text { Code }}$ & $\overline{A / D}$ & $\overline{\text { Code }}$ & $\overline{A / D}$ & $\overline{\text { Code }}$ & $\overline{A / D}$ & $\overline{\text { Code }}$ & $\overline{A / D}$ & $\overline{\text { Code }}$ & $\overline{A / D}$ & $\overline{\text { Code }}$ & $\overline{A / D}$ & $\overline{\text { Code }}$ & $\overline{A / D}$ & $\overline{\text { Code }}$ & $\overline{A / D}$ \\
\hline
\end{tabular}

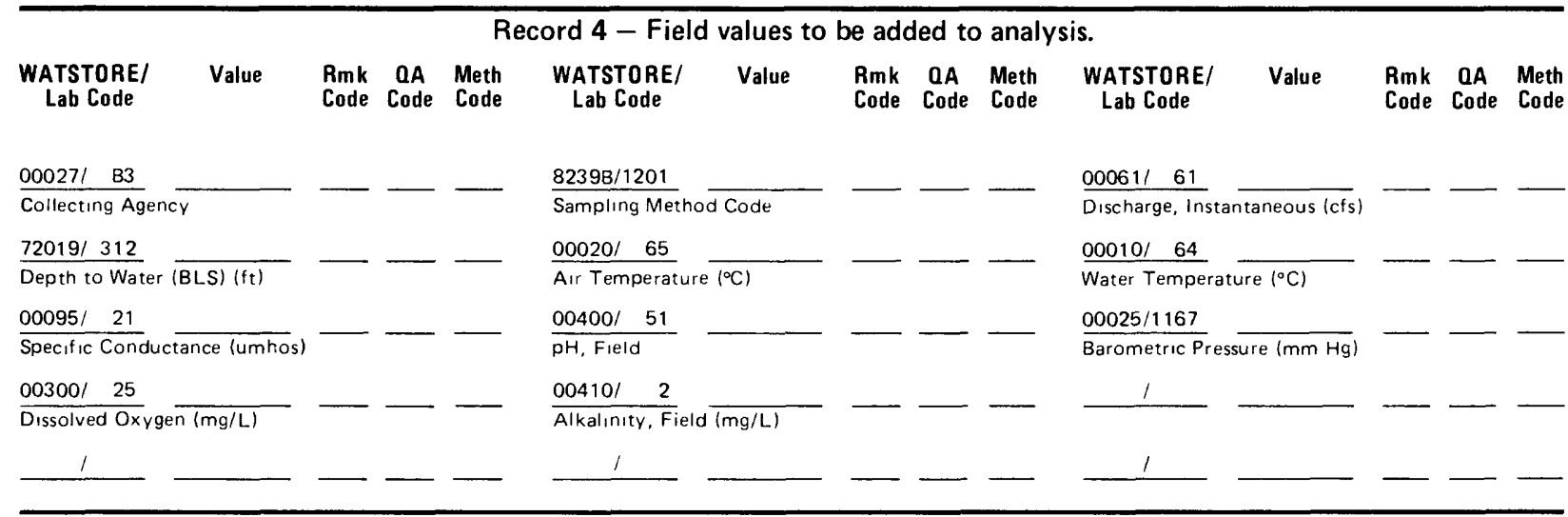

Records 5, 6 - Comments (limit to 138 characters)

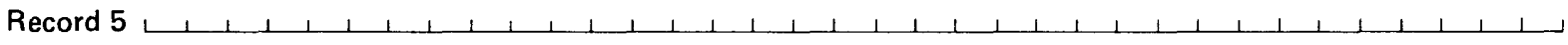

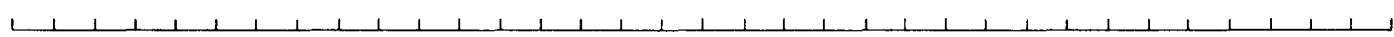

Record $6,1,1,1,1,1,1,1,1,1,1,1,1,1,1,1,1,1,1,1,1,1,1,1$

Total number of sample bottles for this request:

U.S. GOVERNMENT PRINTING OFFICE 679.4831984

Revised $10 / 84$

Figure 2.--U.S. Geological Survey National Water-Quality Laboratory analytical services request form
* - Mandatory for acceptance for laboratory analysis * - Mandatory for storage in WATSTORE 
Temperature, $\mathrm{pH}$, dissolved oxygen (unless $\mathrm{H}_{2} \mathrm{~S}$ is present), and specific conductance will be monitored during purging. A flow-through chamber fitted with probes of field instruments normally will be used for making these measurements, if electrometric meters are used. The chamber must allow a relatively rapid exchange of water. Testing with dye is advisable to determine if any probes might be located in pockets of "dead" water. The dissolved-oxygen probe must be positioned so that a flow velocity of at least one foot per second continually passes it. Closed-top flow-through chambers are recommended so that probes are conveniently held in place and outflow water can be directed away from the work area. Because pressure can affect performance of some electrodes like $\mathrm{pH}$, the outflow of closed-top chambers must be large enough to avoid back pressure, or the flow should be momentarily stopped when measuring parameters with pressure-sensitive probes. Accessory flow-through chambers that attach to the probe package are available for some multiparameter instruments. The probe package of a multiparameter instrument can be used in a simple cylinder having a bottom inflow and open top, but a stirring system will probably be needed to maintain sufficient flow velocity past the dissolved-oxygen probe.

If a flow-through chamber cannot be used, samples of the pump discharge can be collected periodically to make measurements. Samples for measurements sensitive to aeration, such as dissolved oxygen and $\mathrm{pH}$, must be collected to avoid aeration.

Chemical stability is indicated when three successive measurements of the following three monitored parameters, taken at intervals of five minutes or more, differ by less than the following amounts:

Temperature-------------- 0.2 degrees Celsius

Specific conductance-------- 5 percent (or 5 microsiemens per centimeter [uS/cm] when less than $100 \mathrm{us} / \mathrm{cm}$ )

pH-D 0.1 unit

Wells will be considered successfully purged when the discharge water has chemically stabilized with regard to the three monitored parameters and a minimum of three casing volumes of water has been removed. If, however, chemical stability has not been attained after four casing volumes of water have been removed, sampling can be started if notes are made clearly describing the stabilization problem. Continuously operated production wells need to be purged only to chemical stability.

\section{Sampler Selection}

An important consideration when selecting a sampler is the change in water quality that may occur during the process of sampling. Changes may occur in both inorganic and organic constituents. A major concern is often associated with the degassing of volatile organic compounds and outgassing of carbon dioxide and other gases. To reduce cross contamination problems, the interchange of parts between sampling systems (such as pump discharge lines and suspension lines) will be avoided. The types of chemical analyses to be performed determine the kinds of devices that can be used for sampling.

\section{Inorganic Constituents}

Samplers that allow the sample to be aerated may cause changes in the concentrations of some inorganic constituents. Positive displacement pumps (including bladder pumps) and point-source (double valve) bailers with bottomemptying devices are recommended samplers to avoid the introduction of air 
into the sample. Samples for inorganic constituents (including trace metals) should be allowed to contact only glass, Teflon, PVC, and stainless steel before being dis-charged into the sample container (Scalf and others, 1981; Barcelona and others, 1984). Polyethylene materials are not recommended for discharge lines because they tend to adsorb trace metals (Eichholz and others, 1965).

\section{Organic Constituents}

Positive-displacement pumps and point-source bailers having bottomemptying devices are recommended samplers because they have been demonstrated to recover the greatest amount of purgeable organic compounds from water (Imbrigiotta and others, 1988). Samples for organic constituents should be allowed to contact only glass, Teflon, and stainless steel to minimize effects of adsorption or leaching (Pettyjohn and others, 1981; Curran and Thompson, 1983; and Barcelona and others, 1984). Because new materials may leach substances, all new materials will be cleaned before being used.

\section{Descriptions of Recommended Samplers}

The bladder pump is a noncontact, gas-driven pump that can be constructed completely of Teflon and Teflon-coated materials. It uses compressed gas to alternately expand and contract a flexible bladder to force successive pump volumes past a check valve and up through a discharge line. This pump produces a noncontinuous flow.

The helical rotor submersible pump employs an electric motor to turn a helical stainless steel rotor against a semiflexible stator to create a progressing-cavity pumping head. This pump is capable of delivering a continuous stream of water. The samples contact only the stator and stainless steel and Teflon surfaces in the pump.

The gear submersible pump has a set of meshing Teflon gears that form the basis of the pumping system. The gears, driven by an electric motor, act as paddle wheels which push the water along the internal pump walls from the intake point to the pump discharge. The close tolerance of the Teflon gears prevents water from passing back between them. The sample contacts only the stainless steel pump body, the Teflon gears, and discharge tubing.

The point-source bailer is constructed entirely of Teflon and consists of a cylinder with two one-way valves. A one-way valve on the bottom allows water to pass through as it travels downward. After the bailer is lowered to the desired sampling depth, the direction of travel is reversed and a slug of water is retained by the one-way valve. A second one-way valve is positioned at the top of the bailer barrel. The top one-way valve effectively seals off the sample in the bailer as it is retrieved. This prevents exchange with water higher in the well, reduces the potential for degassing of volatile organic compounds during upward travel, and prevents contamination of the sample with particulates scraped from the well casing. The top one-way valve is dislodged with a small rod to allow displacement of the sample with air during sample transfer using a bottom-emptying device.

\section{collecting samples from Wells}

Water-quality constituents to be included in sample analyses for all three ground-water pilot projects are listed in table 7, along with their 
Geological Survey laboratory code or schedule number (Feltz and others, 1985). The water-quality constituents in table 7 represent laboratory analyses.

Field measurements of $\mathrm{pH}$, specific conductance, alkalinity, dissolved oxygen, and temperature also will be made.

After the purging of observation wells, the sampling device will be lowered to just above the well screen or just above the bottom of the casing in open hole wells. In many cases, the pump used for purging can be used to collect samples and thus will be in place.

General sample collection, treatment, and preservation procedures are shown in table 8 . These procedures conform to the requirements of the U.S. Geological Survey National Water-Quality Laboratory (Feltz and others, 1985). The NAWQA schedule numbers shown in table 8 refer to schedules for the NAWQA Program that were created to simplify the completion of laboratory analytical services request forms. For some wells, not all of the constituents referred to in table 8 will be analyzed.

Samples will be collected in a specific order. The suggested order for filling sample bottles is in the order in which the constituent classes are listed in table 8 . Nutrient samples should be the last filtered inorganic samples collected to ensure maximum flushing of surfactants (which interfere with phosphorous analyses) from the filter. To avoid potential problems of mercury contamination, the mercuric chloride ampoules used to preserve the nutrient samples should be added only after the sample collection and handling of other inorganic samples is complete. For temperature, $\mathrm{pH}$, specific conductance, dissolved oxygen, and other parameters monitored during purging, the last recorded values before sample collection will be reported as sample measurements. Alkalinity will be done in the field by incremental titration.

\section{Field Notes}

Complete field notes will be made to record results of instrument calibrations, parameter values during purging, and measurements made during alkalinity titrations. When appropriate, additional observations will address problems experienced with chemical stabilization, sediment, degassing, pre cipitates, odors, and other relevant factors, including observations about the sampling site that may be important for interpretation of potential contamination problems, such as recent application of pesticides, exhaust vapors from the pump generator, and so forth.

\section{Storage and Shipping of Water Samples}

All samples will be packaged according to the instructions provided by the U.S. Geological Survey National Water-Quality Laboratory. Most samples will be packed in ice to reduce geochemical and biological processes. Only samples designated for inorganic constituents (except nutrients) and isotopes can remain unchilled. All samples, except those to be stored for future analyses, such as for stable isotopes and tritium, will be shipped promptly (by air mail or overnight air express, if necessary) to the laboratory--in most cases on the day of collection and always within 4 days of collection. This should allow ample time for sample preparation and analysis so that the maximum holding times recommended by the U.S. Environmental Protection Agency will not be exceeded. The samples will be sent to the laboratory in heavy- 
Table 7.--Water-quality constituents to be included in laboratory analyses for all three ground-water pilot projects, National

Water-Quality Assessment Program

Laboratory code (LC)

or schedule number ( $\mathrm{SH})$

Properties and major constituents

$\mathrm{pH}$

LC0068

Specific conductance

LC0069

Alkalinity

LC0070

Calcium

SH 1043

Magnesium

SH 1043

Potassium

LC0054

Sodium

$\mathrm{SH} 1043$

Chloride

LC1213

Fluoride

SH 1043

Sulfate

LC1200

Silica

SH 1043

Nutrients

Ammonia

LC0301

Nitrite

$\mathrm{LC} 0160$

Nitrite and nitrate

$\mathrm{IC} 0228$

Kjeldahl nitrogen (ammonia plus organic nitrogen)

$\mathrm{IC} 0268$

Soluble reactive phosphorus

LC0162

Major metals and trace elements

Antimony

$\mathrm{LC} 0077$

Arsenic

$\mathrm{IC} 0112$

Barium

$\mathrm{SH} 1043$

Beryllium

SH1043

Boron

$\mathrm{SH} 1043$

Cadmium

SH 1043

Chromium

SH10 43

Cobalt

SH 1043

Copper

SH 1043

Iron

SH10 43

Lead

SH 1043

Lithium

SH 1043

Manganese

$\mathrm{SH} 1043$

Mercury

LC0226

Molybdenum

SH 1043

Nickel

SH 1043

Selenium

LC0087

Silver

SH10 43

Strontium

SH 1043

vanadium

SH 1043

$\mathrm{Zinc}$

SH1043 
Table 7.--Water-quality constituents to be included in laboratory analyses for all three ground-water pilot projects, National Water-Quality Assessment Program--Continued

\section{Radionuclides}

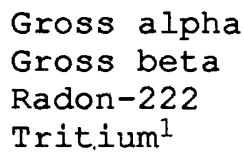

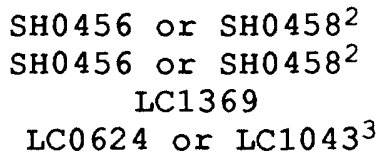

Organic compounds

Dissolved organic carbon

LC 0113

Volatile organic compounds

SH1380

Carbamate insecticides

SH1359

Chlorophenoxy-acid herbicides

SH 0079

Nitrogen-containing pesticides

SH1389

(largely triazine herbicides)

\section{Stable isotope ratios}

Deuterium/protium ${ }^{1}$

LCO 300

Oxygen-18/oxygen $-16^{1}$

LC0 489

${ }^{1}$ Samples should be collected and stored at project office for possible analysis later.

${ }^{2}$ Use SH0456 if estimated concentration of dissolved solids is less than $250 \mathrm{mg} / \mathrm{L}$ and SH0458 otherwise.

${ }^{3}$ Appropriate laboratory method depends on use of data (Robert Michel, U.S. Geological Survey, written commun., 1988). 


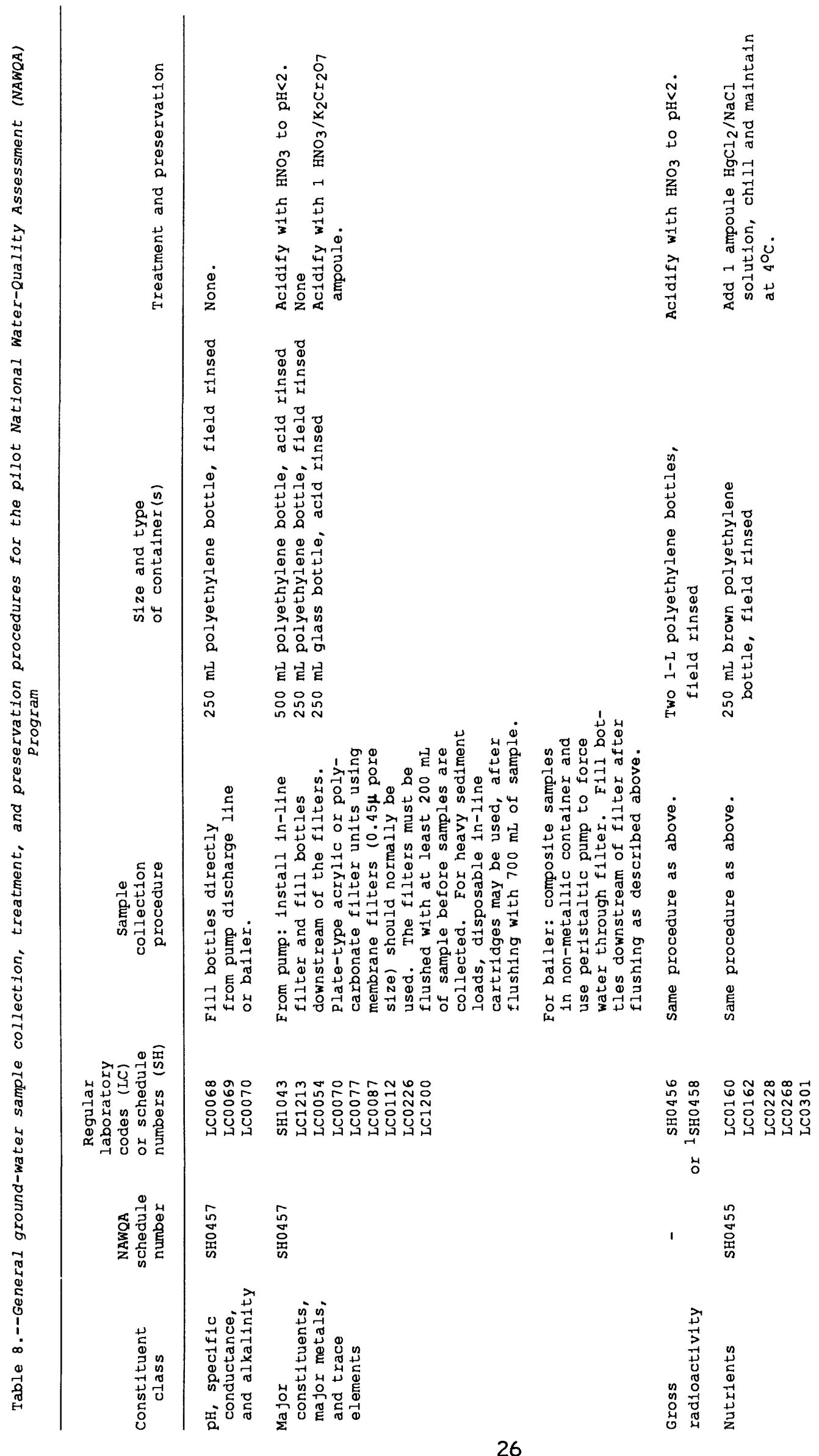




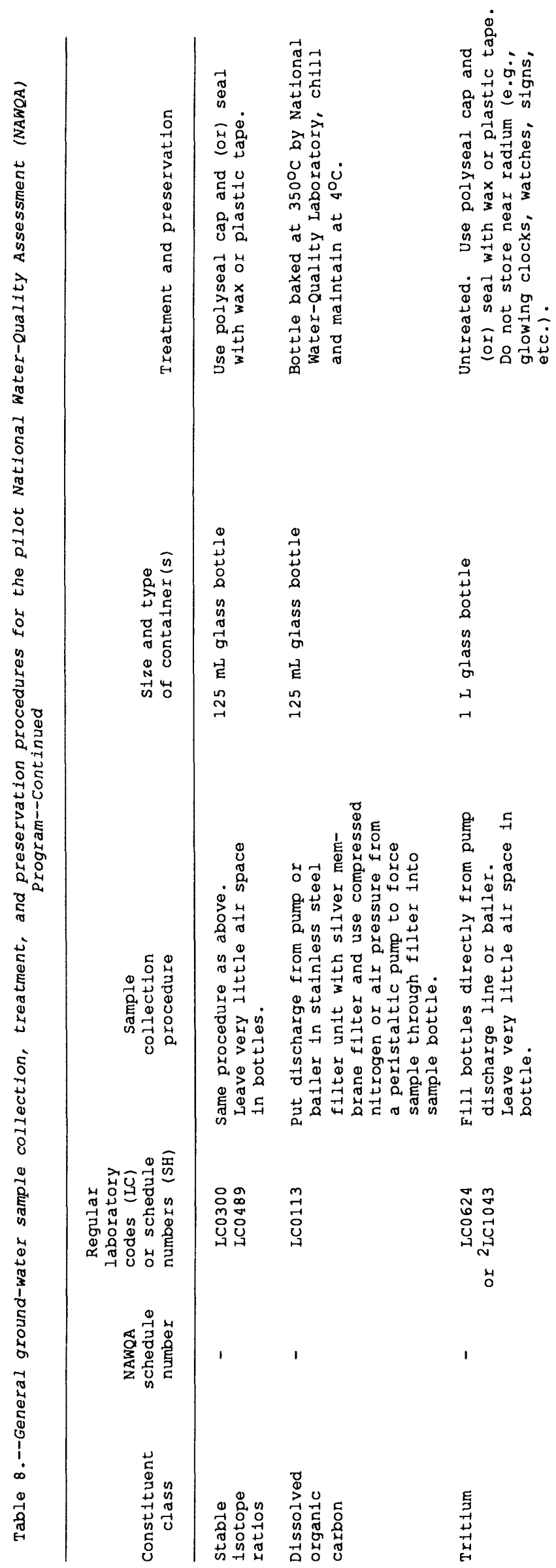




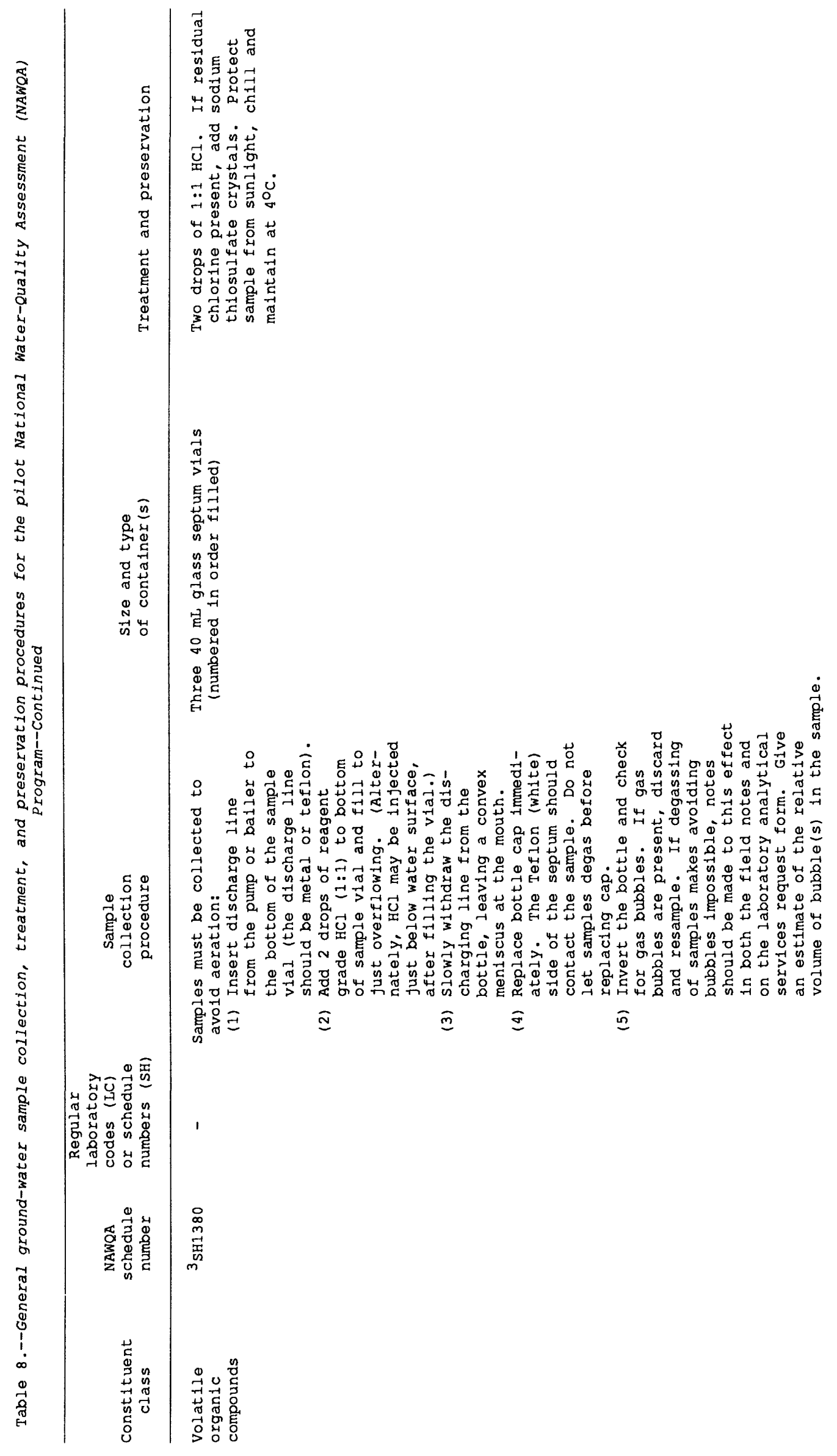




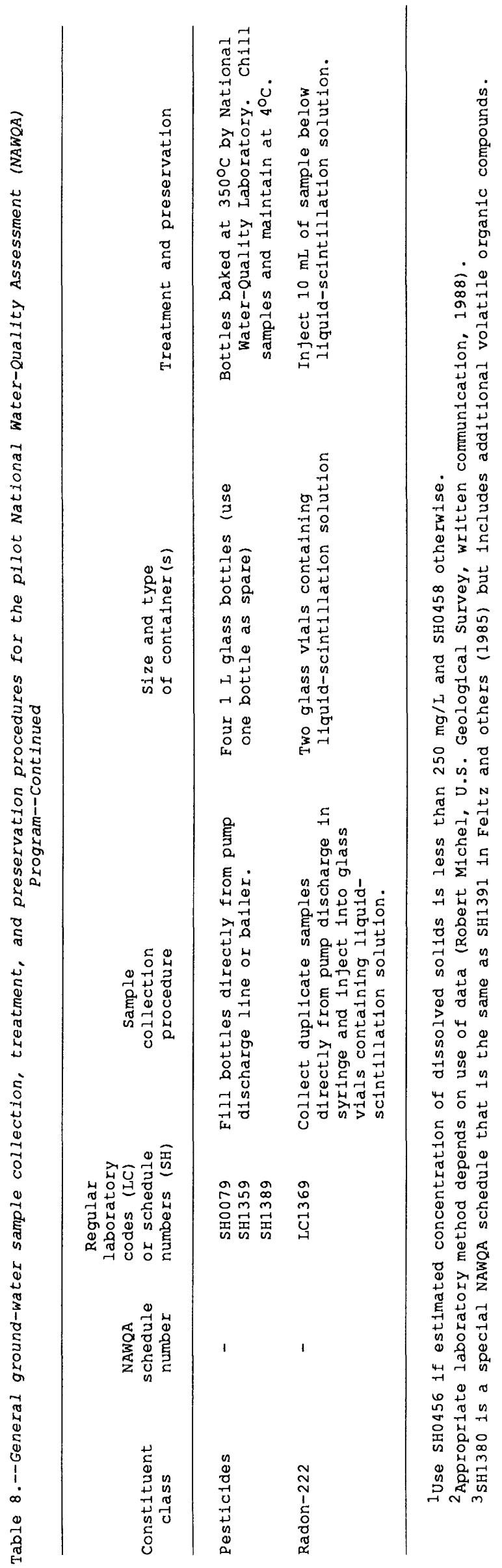


duty coolers. Samples for organic analyses will be collected and sent to avoid the warming of coolers over nonwork days. Samples that require chilling and that are retained for the weekend will be kept at or below $4{ }^{\circ} \mathrm{C}$, but will not be allowed to freeze. A $250-\mathrm{mL}$ bottle of water labeled "Temperature" will be included with each cooler. The National Water-Quality Laboratory Log-In office will return reply cards (or reply sheets) indicating the date that samples were received and the temperature of the water in the "Temperature" bottle. The reply cards will be franked and pre-addressed by the project office or reply sheets enclosed with self-addressed envelopes. Any samples containing hazardous materials or requiring special handling will be clearly marked and the laboratory will be notified in advance that such samples have been sent.

\section{Equipment Cleaning}

The outside and inside of pumps and sampling equipment will be rinsed with clean tap water or, preferably, with deionized water after each site is sampled. After 5 uses, or when contamination from the previous sampling site is suspected, the equipment will be washed in a warm solution of general purpose, phosphate-free laboratory detergent prior to rinsing with tap water, followed by a final rinse with deionized water. New equipment also will be cleaned in this manner to avoid leaching of materials into the samples. Cleaned samplers to be used for collecting inorganic constituents will be stored in clean plastic bags. Cleaned samplers for organic constituents will be stored in aluminum foil.

If contamination is encountered during sampling, pumps and equipment may have to be cleaned with solvents or discarded. Specific needs will have to be determined on a case-by-case basis. Any solvents used must be completely rinsed from the equipment. Wash-blank samples can be analyzed to ensure this.

\section{Project-Submitted Ouality-Assurance Samples}

Quality-assurance samples are collected and submitted to determine the integrity of the sampling results. In particular, these samples are submitted to evaluate potential problems with field conditions, sampling procedures, storage and shipping practices, laboratory methods, and analyst performance, depending on the type and source of the quality-assurance sample. Procedures to test the laboratory methods and the analyst performance are conducted by the U.S. Geological Survey National Water-Quality Laboratory. Each project will submit quality-assurance samples to evaluate the other potential problems. Overall, these project-submitted quality-assurance samples will total approximately an additional 10-15 percent of all samples collected for each study. The kinds of quality-assurance samples to be included are:

Trip blanks - These blanks are used mainly to monitor potential contamination during shipping and storage by diffusion of volatile organic compounds through the septum of the sample bottle. Samples of high-purity laboratory water are bottled under clean conditions in the U.S. Geological Survey National waterQuality Laboratory. These blanks are sent with empty bottles to each project and remain with other samples through the sampling trip and subsequent analyses, but are not opened in the field. 
Field and equipment blanks - These samples consist of high-purity water filled under field conditions, including filtration and addition of preservatives, as appropriate. (For wells sampled with project pumps, this should include running the water through the pumping system.)

Duplicates - These are duplicate water samples that should be bottled in immediate succession.

Spikes - These are water samples containing a measured amount of constituent(s) added at the sampling site.

Duplicate spikes - These are duplicate water samples each containing the same amount of measured constituent(s) added at the site. (Thus, a duplicate spike is two spiked samples submitted in addition to a regular, unspiked sample.)

Reference samples - These samples consist of water containing known quantities of one or more constituents added under controlled laboratory conditions. (Many of the reference samples referred to here are natural water samples spiked in a laboratory. A large number of reference samples are analyzed from a single batch by the U.S. Geological Survey to obtain a statistically reliable estimate of the constituent concentrations.)

The distribution of the type and number of quality-assurance samples will not be equal among the different types of analyses because (1) some types of samples require more comprehensive quality assurance than others, (2) different types of samples may be affected by different conditions, and (3) quality-assurance materials (such as referenced samples) are not available for all sample types. Table 9 shows a suggested overall distribution of quality-assurance samples for the pilot project studies. The number of blanks shown in table 9 refers to field and equipment blanks for all constituents except volatile organic compounds for which trip blanks also are included.

Additional quality assurance targeted at particular locations and (or) at selected constituents may be necessary to uncover problems detected by this quality-assurance program or to further validate key findings in particular pilot project areas. This more intensive quality assurance may utilize additional types of quality-assurance samples. For example, spiked field blanks together with spiked samples may be used to investigate suspected sample-matrix interference effects associated with a particular water type, location, and (or) chemical constituent.

Some additional recommendations in conducting field quality assurance are:

(1) Select wells ahead of time for quality-assurance sampling to help assure good coverage of various field conditions.

(2) Intensify quality assurance when there are significant changes in sample collection procedures, including equipment changes.

(3) Conduct the different types of quality assurance for a particular constituent class at the same sampling sites to help in interpretation of the results. 
Table 9.--Suggested overall distribution of quality-assurance samples

submitted by the ground-water pilot projects to the National Water-Quality Laboratory

[Numbers represent percent of total samples for each type]

\begin{tabular}{|c|c|c|c|c|}
\hline Type & Blanks & $\begin{array}{l}\text { Duplicates } \\
\text { or } \\
\text { triplicates }\end{array}$ & $\begin{array}{l}\text { Duplicate } \\
\text { spikes }\end{array}$ & $\begin{array}{c}\text { Reference } \\
\text { samples }\end{array}$ \\
\hline $\begin{array}{l}\text { Major and minor } \\
\text { ions and } \\
\text { nutrients }\end{array}$ & 2 & 5 & & $\star$ \\
\hline $\begin{array}{l}\text { Dissolved } \\
\text { organic carbon }\end{array}$ & 2 & 10 & & \\
\hline $\begin{array}{l}\text { Gross } \\
\text { radioactivity }\end{array}$ & & $10 \star \star$ & & \\
\hline Radon & & $100 * \star \star$ & & \\
\hline Pesticides & 5 & & 10 & \\
\hline $\begin{array}{l}\text { Volatile } \\
\text { organic } \\
\text { compounds }\end{array}$ & $5-10$ & & $5-10$ & \\
\hline
\end{tabular}

*The USGS Branch of Quality Assurance routinely submits reference samples for inorganic analyses through the Double Blind Sample Program. These comprise about 3-4 percent of the samples submitted to the National Water-Quality Laboratory. The results of these analyses, summarized over the previous 6-month period, are available on a monthly basis.

**The National Water-Quality Laboratory routinely performs this type of quality assurance on about 10 percent of the samples received. Therefore, a duplicate sample should be submitted for about 1 out of every 10 samples submitted for gross alpha and gross beta analysis. Label as "Use for Lab Duplicate." Send in a single log-in sheet for both samples, and write at the bottom, under the Remarks section, a note that a duplicate sample has been included. The laboratory will submit most of these extra samples as duplicates or spikes and report the results to the project.

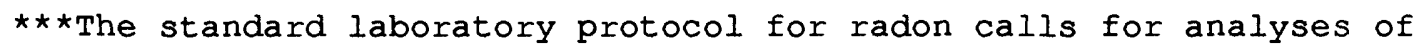
duplicate samples submitted by the projects. 


\section{SUMMARY}

Several pilot projects are being conducted as part of the National Water-Quality Assessment (NAWQA) Program. The purpose of the pilot program is to test and refine concepts for a proposed full-scale program. Three of the pilot projects are specifically designed to assess ground water.

The purpose of this report is to describe the criteria that are being used in the NAWQA pilot projects for selecting and documenting wells, installing new wells, and sampling wells for different water-quality constituents. The report was prepared specifically for the NAWQA pilot projects and is not intended to be a general purpose field manual.

Guidelines are presented for the selection of wells for sampling. Information needed to accurately document each well includes site characteristics related to the location of the well, land use near the well, and important well construction features. These guidelines ensure the consistency of the information collected and will provide comparable data for interpretive purposes.

Guidelines for the installation of wells are presented and include procedures that need to be followed for preparations prior to drilling, the selection of the drilling technique and casing type, the grouting procedure, and the well-development technique. Information needed to adequately document the installation of these wells is presented.

A major component of the protocols is related to water-quality sampling. Tasks are identified that need to be completed prior to visiting the site for sampling. Guidelines are presented for purging the well prior to sampling, both in terms of the volume of water pumped and the chemical stability of field parameters. Guidelines are presented concerning sampler selection as related to both inorganic and organic constituents. Documentation needed to describe the measurements and observations related to sampling each well and treating and preserving the samples are also presented.

Procedures are presented for the storage and shipping of water samples, equipment cleaning, and quality assurance. Quality-assurance guidelines include the description of the general distribution of the various qualityassurance samples (blanks, spikes, duplicates, and reference samples) that will be used in the pilot program. 


\section{REFERENCES}

Barcelona, M. J., Gibb, J. P., and Miller, R. A., 1984, A guide to the selection of materials for monitoring well construction and groundwater sampling: Illinois State Water Survey for U.S. Environmental Protection Agency, Report Number EPA-600/2-84-024, 78 p.

Bennett, G. D., and Rosenshein, Joseph, eds., 1984, Groundwater hydraulics: American Geophysical Union, Water Resources Monograph Series, v. 9, $420 \mathrm{p}$.

Claassen, H. C., 1982, Guidelines and techniques for obtaining water samples that accurately represent the water chemistry of an aquifer: U.S. Geological Survey Open-File Report 82-1024, 49 p.

Curran, C. M. and Thompson, M. B., 1983, Leaching of trace metal organics into water from five common plastics: Ground Water Monitoring Review, v. 3, no. 3, p. 68-71.

Davis, R. E., Foote, F. S., and Kelly, J. W., 1966, Surveying: Theory and practice: McGraw-Hill, New York, 1,096 p.

Driscoll, F. G., 1986, Groundwater and Wells (2d ed.): Johnson Division, St. Paul, 1,108 p.

Eichholtz, G. G., Nagel, A. E., and Hughes, R. B., 1965, Adsorption of ions in dilute aqueous solutions on glass and plastic surfaces: Analytical Chemistry, v. 37, no. 7, p. 863-868.

Feltz, H. R., Duncan, S. S., and zepp, Ann, 1985, 1986-87-88 National WaterQuality Laboratory services catalog: U.S. Geological Survey Open-File Report 86-232, 69 p.

Finkelstein, K., and Prins, D. D., 1981, An inexpensive portable vibra-coring system for shallow water and land applications: Coastal Engineering Research Center Technical Aid 81-8, 15 p.

Freeze, R. A., and Cherry, J. A., 1979, Groundwater: Englewood Cliffs, N.J., Prentice Hall, 604 p.

Gillham, R. W., Robin, M. J. L., Barker, J. F., and Cherry, J. A., 1983, Groundwater monitoring and sample bias: American Petroleum Institute, Publication $4367,206 \mathrm{p}$.

Heath, R. C., 1983, Basic ground-water hydrology: U.S. Geological Survey Water-Supply Paper 2220, $84 \mathrm{p}$.

Hirsch, R. M., Alley, W. M., and Wilber, W. G., 1988, Concepts for a National Water-Quality Assessment Program: U.S. Geological Survey Circular 1021, 42 p.

Hurr, R. T., 1966, A new approach for estimating transmissivity from specific capacity: water Resources Research, v. 2, no. 4, p. 657-664. 
Imbrigiotta, T. E., Gibs, Jacob, Fusillo, T. V., Kish, G. R., and Hochreiter, J. J., 1988, Field evaluation of seven sampling devices for purgeable organic compounds in ground water; in Collins, A. G., and Johnson, A. J., eds., Ground-water Contamination: Field Methods, ASTM STP 963: American Society for Testing and Materials, Philadelphia, Pa., p. 258-273.

Keely, J. F., and Boateng, Kwasi, 1987a, Monitoring well installation, purging, and sampling techniques-Part 1: Conceptualizations: Ground Water, v. 25 , no. 3, p. 300-313.

----1987b, Monitoring well installation, purging, and sampling techniquesPart 2: Case histories: Ground Water, v. 25, no. 4, p. 427-439.

Lohman, S. I., 1972, Ground-water hydraulics: U.S. Geological Survey Professional Paper 708, 70 p.

Mattraw, H. C., Jr., Wilber, W. G., and Alley, W. M., 1989, Quality-assurance plan for the pilot National Water-Quality Assessment Program: U.S. Geological Survey Open-File Report 88-726, 21 p.

McClymonds, N. E., and Franke, O. L., 1972, Water-transmitting properties of aquifers on Long Island, New York: U.S. Geological Survey Professional Paper 627-E, $24 \mathrm{p}$.

McDonald, M. E., and Harbaugh, A. W., 1988, A modular three-dimensional finite-difference ground-water flow model: U.S. Geological Survey Techniques of Water-Resources Investigations, Book 6, Chapter A1, 586 p.

Office of Water Data Coordination, 1977, National handbook of recommended methods for water-data acquisition: U.S. Geological Survey, 872 p.

Pettyjohn, W. A., Dunlap, w. J., Cosby, R., and Keeley, J. W., 1981, Sampling ground water for organic contaminants: Ground Water, v. 19, no. 2, p. $180-188$.

Reed, J. E., 1980, Type curves for selected problems of flow to wells in confined aquifers: U.S. Geological Survey Techniques of Water-Resources Investigations, Book 3, Chapter B3, 106 p.

Reilly, T. E., 1984, A Galerkin finite-element flow model to predict the transient response of a radially symmetric aquifer: U.S. Geological Survey Water-Supply Paper 2198, 33 p.

Reilly, T.E., Franke, O. L., and Bennett, G. D., 1989, Bias in groundwater samples caused by wellbore flow: Journal of Hydraulic Engineering, v. 115, no. 2, p. 270-276.

Richter, H. R., and Collentine, M. G., 1983, will my monitoring wells survive down there?: Design installation techniques for hazardous waste studies, in Proceedings of the Third National Symposium on Aquifer Restoration and Ground-Water Monitoring: D. M. Nielsen, ed., National Water well Association, Worthington, Ohio, $461 \mathrm{p}$.

Scalf, M. R., McNabb, J. F., Dunlap, W. J., Cosby, R. L., and Fryberger, John, 1981, Manual of ground-water quality sampling procedures: U.S. Environmental Protection Agency Report Number 600/2-81-160, 93 p. 
Shuter, Eugene, and Teasdale, W. E., 1989, Application of drilling, coring, and sampling techniques to test holes and wells: U.S. Geological Survey Techniques of Water-Resources Investigations, Book 2, Chapter F1, 97 p.

Stallman, R. W., 1971, Aquifer-test design, observation, and data analysis: U.S. Geological Survey Techniques of Water-Resources Investigations, Book 3, Chapter B1, 26 p.

Wolff, R. G., 1982, Physical properties of rocks--porosity, permeability, distribution coefficients, and dispersivity: U.S. Geological Survey Water-Resources Investigations Report 82-166, $118 \mathrm{p}$.

Wood, W. W., 1976, Guidelines for collection and field analysis of groundwater samples for selected unstable constituents: U.S. Geological Survey Techniques of Water-Resources Investigations, Book 1, Chapter D2, 24 p. 